\title{
Bach'ın Müziği ve Matematik
}

\author{
Melis Saylaç ${ }^{1}$ \\ ${ }^{1}$ Affiliation not available
}

June 8, 2020

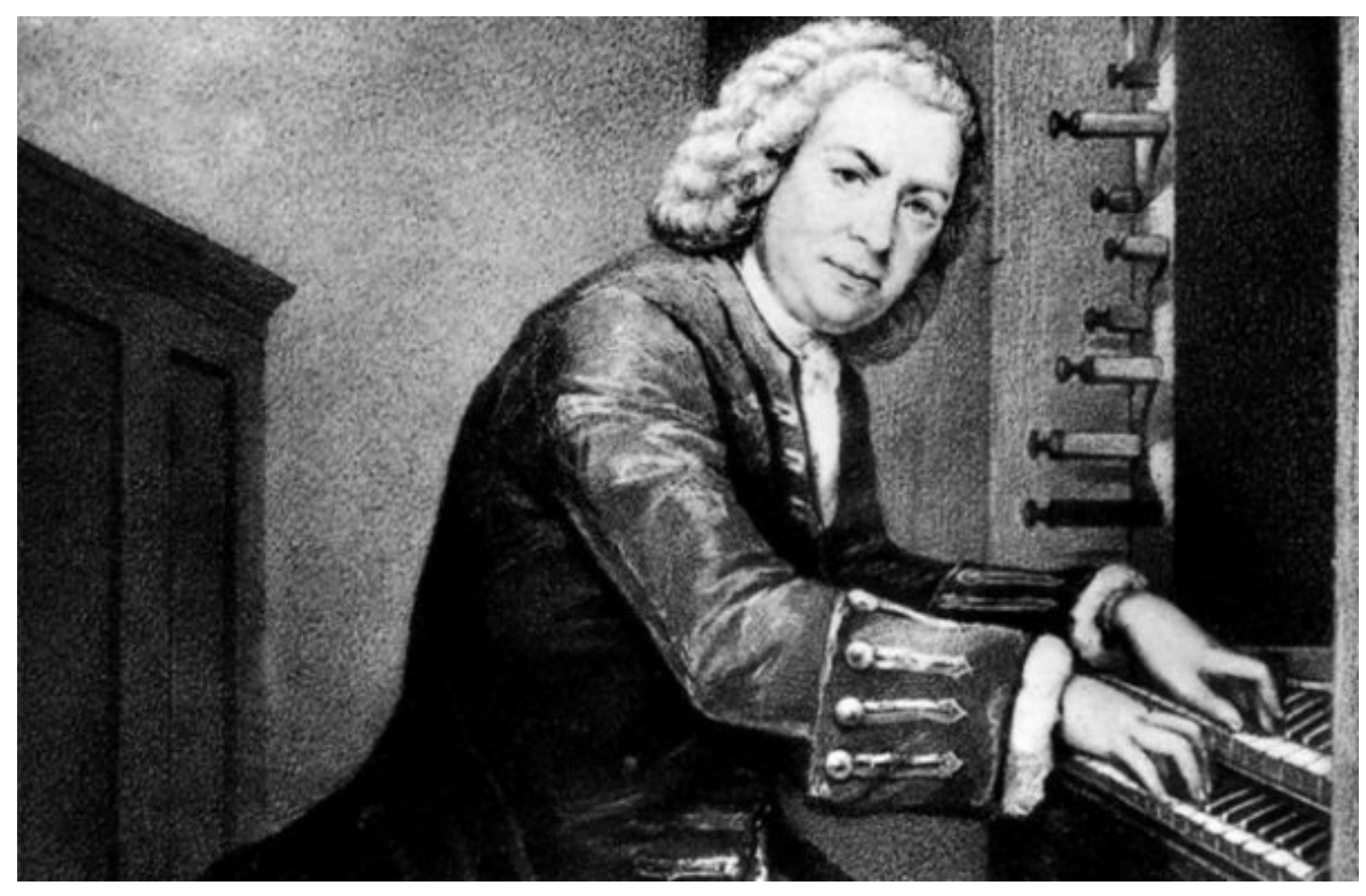

Figure 1: Bach'ın Matematikle Çevrili Büyülü Dünyası

Johann Sebastian Bach, 21 Mart 1685 doğumlu Alman barok müzik bestecisi ve orgcudur. Bach 19. yüzyılda müziğinin tekrar çalınmaya başlaması ve ilginin tekrar canlanmasına kadar kendi döneminde büyük bir besteci olarak bilinmemiş ancak bugün en büyük bestecilerden biri olarak kabul edilir.

Bilginler ve müzisyenler yıllarca matematiği kullanarak müzikleri analiz ettiler, hatta yarattılar. Birçok iyi besteci müziğin altında yatan matematik ilkelerinin derin anlamını kavrayabildi. Bunlardan bir tanesi ise görkemli Johann Sebastian Bach'tır. Bach'ın besteleri dahiliğinin bir parçası olsa da aslında onların temelinde de basit matematik vardır.

Matematikçiler çalışmalarının estetiksel yönünü vurgulamaktan çekinmezler. Hem matematik hem müzik ikisine de desenler hakimdir. Matematikçinin kalıpları, bestecinin kalıpları gibi güzel olmalı; fikirler uyumlu bir şekilde bir araya gelmelidir. 
G.H. Hardy'nin dediği gibi, "Güzellik ilk testtir: dünyada çirkin matematik için kalıcı bir yer yoktur."

\section{Simetri}

Simetri aslında müziğin temel yönüdür bu nedenle ,simetri için matematiksel çerçeve olan, grup teorisinin müzikal analize uygulanması şaşırtıcı değildir. Transpozisyon, inversiyon ve retrogression müzikal teknikleri grup işlemleri olarak yorumlanabilir ve bu bakış açısı eski kompozisyonlar üzerine yeni bir ışık tutmuştur. Birçok besteci geometrik dönüşümleri bir kompozisyon cihazı olarak kullanmıştır. Dönüşümler ve simetriler, bestecilerin kreasyonlarını zenginleştirmeleri için bir dizi araç olarak düşünülebilir. Böylece, seçilen bir tema, varyasyonlar üretmek için zaman içinde aktarılabilir, tersine çevrilebilir veya yansıtılabilir.(Lynch, 2017)

Bir besteci karşı noktaya odaklandığında, vurgu, müziğin dikey eksenine (Akorlar ve uyum) değil, yatay eksene (melodi telleri) yerleştirilir böylece çalışmanın amacı, aynı anda gerçekleşen çeşitli müzikal çizgiler arasındaki etkileşim haline gelir.

Kanon*larla yaratıcı olmanın her türlü yolu vardır. Cevap, konunun kesinlikle birebir bir kopyası olmak yerine, aslında geriye doğru, baş aşağı, çift hızda ya da yarım hızda ya da bunlardan herhangi birinin bir kombinasyonu olabilir. Kuralları katıdır, ancak birkaç önemli seçenek sayesinde mevcut olasılıklar sonsuzdur.

Asıl zorluk, bu tür müziğin iyi bir ses çıkarmasıdır: sadece öngörülen kuralları takip etmek, sonucun hoß̧ veya ilginç olacağına dair bir garanti değildir, bu nedenle hem uygun malzeme bulmak hem de hangi kuralların en iyi şekilde uygulanacağını belirlemek için büyük bir estetik arıtma gereklidir. Bu da Bach'ın mükemmel olduğu kısımdır.

Bach (1685-1750) hiçbir şekilde bu tarz bir kompozisyonun mucidi değildi. Buxtehude ve Schütz gibi 17.yüzyıl Kuzey Alman öncüllerinden miras aldı ama kanonun kabul edilen büyük ustasıydı (hala öyle) ve çalışmaları Batı müziğindeki zirvesini temsil ediyor. Onun özel dehası sadece karşı notayı ustalıkla ele alma meselesi değil, aynı zamanda büyük bir aralık ve duygu derinliğini ifade etme ve bu matematik-y tekniklerini sarsılmaz bir disiplinle kullanarak dengeli, güzel orantılı kompozisyonlar üretme yeteneğiydi.(Lindsay, 2017)

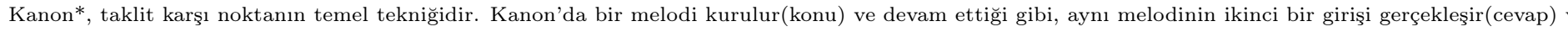

\section{Goldberg Varyasyonları}

Genel bir arka plan olarak, Goldberg varyasyonları 2 arya ve 30 varyasyondan oluşan klavsen için yazılmış bir eserdi. Bach, Lutheran olan son derece dindar bir adamdı ve bu parçada kullandığı iki kavram birlik ve üçlü fikirlerdi. Genel gözlemler, her biri 32 çubuklu 3, 9, 21 ve 30 varyasyonları ve 95 barlı varyasyon 16 hariç olmak üzere, varyasyonların hepsinin 64 bara sahip olduğunu içerir.

\begin{tabular}{|c|c|c|c|c|c|c|c|c|}
\hline \multicolumn{9}{|c|}{ Classical Latin alphabet } \\
\hline Letter & A & B & c & D & E & $\mathbf{F}$ & G & H \\
\hline Latin name & $A \cdot \boldsymbol{a}$ & $B E \cdot b e$ & $c e \cdot \infty$ & $D E \cdot d \theta$ & E. $\theta$ & EF-ef & $G E \cdot g \theta$ & $m a \cdot h a$ \\
\hline Latin pronunciation (IPA) & lat & loes & /kes & /des/ & les/ & /et! & /get & mal \\
\hline Letter & 1 & $\mathbf{K}$ & L & M & $\mathrm{N}$ & 0 & $\mathbf{P}$ & Q \\
\hline Latin name & $I \cdot r$ & $k a \cdot k a$ & $\mathrm{E} \cdot \mathrm{el}$ & $\mathrm{eM} \cdot \mathrm{em}$ & en:en & 0.0 & $P E \cdot p \theta$ & $a v \cdot q u$ \\
\hline Latin pronunciation (IPA) & fit/ & /ka: & $/ \varepsilon V$ & $\mathrm{lem} /$ & Ien/ & $10 \%$ & /pe: I & /kus' \\
\hline Letter & $\mathbf{R}$ & $\mathbf{s}$ & $\mathbf{T}$ & $\mathbf{v}$ & $x$ & $\mathbf{Y}$ & z & \\
\hline Latin name & $\mathrm{eA} \cdot \mathrm{er}$ & $\mathrm{Es} \cdot \mathrm{es}$ & $\mathrm{Te} \cdot \mathrm{te}$ & $8 \cdot 0$ & $x \cdot i x$ & $\begin{array}{l}\text { I GRAEcA. } \\
\text { I Graeca }\end{array}$ & zETA- zeta & \\
\hline Latin pronunciation (IPA) & lerl & $/ \varepsilon s /$ & nes $/$ & $\mathrm{NuJ}$ & /iks/ & fe granka/ & /dzeta/ & \\
\hline
\end{tabular}


Bu Cevapla, sayma Roma alfabesine (veya Latin alfabesine) dayanır, bunun gibi:

- Varyasyon 2, 129. barda başlar. $129=3$ x 43 ve $43=\mathrm{C}+\mathrm{R}+\mathrm{E}+\mathrm{D}+\mathrm{O}$. Credo, Latince Hıristiyan Kilisesi'nin bir inancıdır.

- Varyasyon 3, bar 193 ile başlar. 1 birlik, 3 üçlük, 9 üçlüğ̈̈n bir üç parçalı tablosu $\left(3^{*} 3^{*} 3\right)$.

- Varyasyon 6, çubuk 353'te başlar. 6 ilk mükemmel sayıdır. Varyasyon 6, bar 416'da biten 64 bara sahiptir. $416=2^{\wedge} 5 \times 13$ (triunity tekrar). $41=\mathrm{J}+\mathrm{S}+\mathrm{B}+\mathrm{A}+\mathrm{C}+\mathrm{H}$. varyasyon 11 , önceki 416'ya karşllk gelen 641 barında başlar.

- Varyasyon 15, bar 960 ile biter. $960=2 \times 10$ x 48, $48=\mathrm{I}+\mathrm{N}+\mathrm{R}+\mathrm{I}$. INRI, "Yahudilerin Kralı İsa " anlamina gelen Latince ifadenin kisaltmasıdır.

Şimdi bazılarınız tüm bunların sadece bizim açımızdan bir analiz olabileceğini veya bunlarla Bach'ın gerçekten neyi kastettiğini düşünüyor olabilir. Bu parçadaki matematiksel olayların tam olarak ne kadarının Bach tarafından tasarlandığından ve bizimle aynı şekilde hesaplandığından emin olamayız. Bununla birlikte, bu tür olayların sayısı, parçaya hiçbir matematiksel düşünce biçiminin konulmamasını son derece olası kılmaktadır.(Tay, 2016)

Bununla alakalı daha çok şey öğrenmek isterseniz şu sitelere de bir bakmanızı öneririm :

Music, Mathematics and Bach: https://www.ias.ac.in/article/fulltext/reso/004/05/0061-0070

Bach, Music+Math: Symmetry https://youtu.be/Z8dKLbmGUbI

Kaynakça: https://www.irishtimes.com/news/science/the-mathematician-s-patterns-likethose-of-the-composer-must-be-beautiful-1.3096020

https://www.quora.com/What-is-meant-by-"Bach-was-a-mathematical-composer

https://www .quora.com/What-is-the-relation-between-Bachs-music-and-math 